\title{
Mamadou Ould Dahmed, Le Héros monstrueux, une lecture psychanalytique du personnage romanesque de Stendhal
}

Nicolas Allard

\section{(2) OpenEdition Journals}

Édition électronique

URL : http://journals.openedition.org/studifrancesi/5366

DOI : 10.4000/studifrancesi.5366

ISSN : 2427-5856

Éditeur

Rosenberg \& Sellier

\section{Édition imprimée}

Date de publication : 1 décembre 2016

Pagination : $539-540$

ISSN : 0039-2944

\section{Référence électronique}

Nicolas Allard, « Mamadou Ould Dahmed, Le Héros monstrueux, une lecture psychanalytique du personnage romanesque de Stendhal », Studi Francesi [En ligne], 180 (LX | III) | 2016, mis en ligne le 01 janvier 2017, consulté le 18 septembre 2020. URL : http://journals.openedition.org/studifrancesi/5366 ; DOI : https://doi.org/10.4000/studifrancesi.5366

Ce document a été généré automatiquement le 18 septembre 2020.

\section{cc) $(9)$}

Studi Francesi è distribuita con Licenza Creative Commons Attribuzione - Non commerciale - Non opere derivate 4.0 Internazionale. 


\title{
Mamadou Ould Dahmed, Le Héros monstrueux, une lecture psychanalytique du personnage romanesque de Stendhal
}

\author{
Nicolas Allard
}

\section{RÉFÉRENCE}

MAMADOU OULD DAHMED, Le Héros monstrueux, une lecture psychanalytique du personnage romanesque de Stendhal, Paris, L'Harmattan, 2015, 233 pp.

1 Dans son ouvrage Le Héros monstrueux, une lecture psychanalytique du personnage romanesque de Stendhal, Mamadou Ould Dahmed, maître de conférences à la Faculté des Lettres de Nouakchott, propose une étude relativement originale de l'œuvre stendhalienne. En effet, alors même que les recherches mêlant psychanalyse et littérature semblent peu à peu tomber en désuétude, Mamadou Ould Dahmed choisit d'en faire la pierre de touche de son ouvrage. En se focalisant principalement sur quatre romans stendhaliens (Armance, Le Rouge et le Noir, La Chartreuse de Parme, Lucien Leuwen), le critique cherche à démontrer la pertinence d'une appréhension freudienne des personnages masculins de ces romans. Il oppose ainsi systématiquement le personnage du fils (Octave, Julien, Fabrice, Lucien) au personnage du père. Son étude est composée de deux grandes parties.

Dans un premier temps, Mamadou Ould Dahmed évoque ce qu'il choisit d'appeler «le complexe parental». Cette partie est une réflexion sur les rôles tenus par les pères et mères de ces quatre romans stendhaliens. Le père est présenté comme une figure négative: à la fois intrigant et tyrannique, il s'oppose au plein épanouissement du fils. La mère ne relève pas de la même négativité, mais elle est décrite bien souvent comme possessive et castratrice. Cette première partie n'est certes pas dénuée d'intérêt, mais 
elle s'avère relativement longue. On peut alors légitimement se demander les raisons pour lesquelles cette étude s'intitule Le héros monstrueux. Non seulement il est assez peu question de ceux que Mamadou Ould Dahmed considère comme les figures héroïques de ces récits (Octave, Julien, Fabrice, Lucien), mais on ne voit pas nécessairement en quoi la psychanalyse s'avère être d'un apport décisif aux études stendhaliennes. Les parents des jeunes gens sont certes analysés avec soin, mais nous n'apprenons finalement rien de réellement neuf à leur sujet. Il s'agit là d'une déception, le recours à la psychanalyse - chose peu fréquente dans les études stendhaliennes - pouvant laisser augurer le développement d'un certain nombre de réflexions novatrices.

La seconde partie de l'ouvrage manifeste explicitement le déséquilibre souligné plus haut: elle s'intitule en effet «Le héros monstrueux». Si un chapitre sur cette notion est, en soi, tout à fait envisageable, le procédé parait peu pertinent si l'on tient compte du fait que ce sous-titre est le même que le titre de l'ouvrage. Cette seconde partie présente toutefois l'intérêt d'entrer enfin dans le vif du sujet. Elle se compose de trois grands moments: «les symptômes scandaleux du héros monstrueux», «leurres et lueurs de la fonction scopique», «l'enfance de la révolte». Le premier de ces trois chapitres est réellement en phase avec le titre de l'ouvrage. On peut néanmoins regretter l'absence de définition du syntagme «héros monstrueux». Cette notion semble aller de soi pour l'auteur, alors même qu'elle aurait mérité d'être interrogée. Les deux derniers chapitres de l'œuvre sont certes intéressants, mais semblent parfois étrangement détachés du thème annoncé par le titre.

De manière générale, l'étude, qui se veut comparatiste, ne fait que trop rarement intervenir des rapprochements entre les différents personnages. Certaines sous-parties sont ainsi spécifiques à Fabrice del Dongo, d'autres à Julien Sorel, d'autres à Octave de Malivert... La conclusion met en exergue le caractère assez peu structuré de l'ensemble. À la fin de la lecture de cet ouvrage se pose toujours la question de ce qu'est réellement un héros monstrueux. Mamadou Ould Dahmed semble surtout avoir voulu montrer - ce qui est en soi une tentative tout à fait honorable - que la psychanalyse était applicable à l'étude de l'œuvre stendhalienne. On peut ainsi avoir le sentiment que le thème du héros monstrueux n'est pas le centre de son étude, mais un élément - certes important - parmi d'autres.

5 Le recours à la psychanalyse a donné lieu à des interprétations intéressantes, bien que certaines ne soient pas totalement neuves. D'autres interprétations semblent en revanche nettement plus discutables. Les symboles phalliques, du fait de leur récurrence dans la démonstration, finissent par ne plus paraître opérants. L'évocation systématique de l'homosexualité supposée des personnages masculins dénature quant à elle ce que sont fondamentalement ces quatre récits stendhaliens.

6 Signalons enfin, même si là n'est pas l'essentiel, que l'ouvrage aurait gagné à être retravaillé avant d'être publié. On déplore en effet un nombre non négligeable de fautes d'orthographe, ainsi que quelques fautes de style. L'auteur a choisi en outre de s'appuyer sur un nombre de références critiques assez limité (Philippe Berthier, pourtant en charge de la nouvelle édition des Euvres romanesques complètes de Stendhal pour la «Bibliothèque de la Pléiade», n'est à aucun moment cité, pas même dans la bibliographie...) et, parfois, sur des références littéraires fausses (on nous dit que ce n'est pas Montesquieu, mais Diderot, qui est l'auteur des Lettres persanes...). On conseillera la lecture de cet ouvrage aux stendhaliens qui seraient curieux de voir, sur plus de deux cents pages, l'application de la méthode psychanalytique à quatre des plus 
fameux romans d'Henri Beyle. Si certaines interprétations sont tout à fait intéressantes et stimulantes, l'ensemble de cette étude paraît à la fois trop déstructuré et trop détaché de la poétique stendhalienne pour devenir à terme un ouvrage de référence sur l'écrivain grenoblois. 